\title{
Effects of aquaporin 4 and inward rectifier potassium channel 4.1 on medullospinal edema after methylprednisolone treatment to suppress acute spinal cord injury in rats ${ }^{1}$
}

\author{
Ye Li', Haifeng Hu", Jingchen Liu'", Qingsan Zhu'v, Rui Guv
}

'Associate Professor, Department of Orthopaedics, China-Japan Union Hospital, Jilin University, Changchun, China. Conception, design, intellectual and scientific content of the study; acquisition of data; manuscript writing; critical revision.

"Attending Doctor, Department of Orthopaedics, China-Japan Union Hospital, Jilin University, Changchun, China. Acquisition of data, manuscript writing.

I'Professor, Department of Orthopaedics, China-Japan Union Hospital, Jilin University, Changchun, China. Scientific content of the study, acquisition of data, manuscript writing.

IVProfessor, Department of Orthopaedics, China-Japan Union Hospital, Jilin University, Changchun, China. Acquisition of data.

${ }^{\vee}$ Professor, Department of Orthopaedics, China-Japan Union Hospital, Jilin University, Changchun, China. Intellectual, scientific, conception and design of the study; critical revision.

\begin{abstract}
Purpose: To investigate the effects of aquaporin 4 (AQP4) and inward rectifier potassium channel 4.1 (Kir4.1) on medullospinal edema after treatment with methylprednisolone (MP) to suppress acute spinal cord injury (ASCI) in rats.

Methods: Sprague Dawley rats were randomly divided into control, sham, ASCl, and MPtreated $\mathrm{ASCl}$ groups. After the induction of $\mathrm{ASCl}$, we injected $30 \mathrm{mg} / \mathrm{kg} \mathrm{MP}$ via the tail vein at various time points. The Tarlov scoring method was applied to evaluate neurological symptoms, and the wet-dry weights method was applied to measure the water content of the spinal cord.

Results: The motor function score of the $\mathrm{ASCl}$ group was significantly lower than that of the sham group, and the spinal water content was significantly increased. In addition, the levels of AQP4 and Kir4.1 were significantly increased, as was their degree of coexpression. Compared with that in the $\mathrm{ASCl}$ group, the motor function score and the water content were significantly increased in the MP group; in addition, the expression and coexpression of AQP4 and Kir4.1 were significantly reduced.

Conclusion: Methylprednisolone inhibited medullospinal edema in rats with acute spinal cord injury, possibly by reducing the coexpression of aquaporin 4 and Kir4.1 in medullospinal tissues.

Key words: Methylprednisolone. Spinal Cord Injuries. Aquaporin 4. Potassium Channels. Rats.
\end{abstract}




\section{Introduction}

Acute spinal cord injury (ASCl) is a trauma-induced spinal cord disorder; current research mainly focuses on preventing secondary spinal cord injuries, promoting regeneration of the spinal cord, and replacing the injured medullospinal tissues ${ }^{1}$. Spinal cord injuries are usually divided into primary and secondary injuries; the former refers to direct and irreversible tissue injury to the spinal cord, which may be followed by secondary spinal cord injury. Injury results in the release of a large number of self-destructive mediators that lead to hypoxia-ischemia, edema, degeneration, and necrosis of the spinal cord ${ }^{2}$. Therefore, protecting the uninjured portions of the spinal cord and suppressing medullospinal edema are the key early treatments for ASCI. However, the mechanisms of $\mathrm{ASCl}$-induced medullospinal edema are still unclear. Aquaporins (AQPs) are closely related to tissue edema and AQP4 is the most studied isoform in the central nervous system, as it is widely distributed in the brain and spinal cord; it is closely related to trauma-induced brain and medullospinal edema. Oklinski et $a l^{3}$ found that AQP4 is mainly expressed in the astrocytes of the rat spinal cord, as well as in the gray matter and white matter of the spinal cord; it is most highly expressed on the membranes of perivascular astrocytes in the gray matter. AQP4 participates in the transportation of water molecules in the brain, as well as the regulation of electrolytes and osmotic pressure, in the physiological state; under pathological conditions, it is involved in tissue edema caused by bodily injury ${ }^{4}$. Overexpression of AQP4 in the gray matter of the spinal cord indicates that AQP4 might play an important role in regulating the water balance of the spinal cord. Inward rectifier potassium channel 4.1 (Kir4.1) participates in not only the formation of action potentials, but also water transportation, in brain tissues ${ }^{5}$. The expression of Kir4.1 in rats with focal cerebral ischemia/reperfusion positively correlated with the degree of brain edema, and Kir4.1 was transported by AQP4-coupled mediating water $^{6}$. However, the combined effects of Kir4.1 and AQP4 on medullospinal edema secondary to spinal cord injury have not been reported.

Methylprednisolone (MP) is the most widely studied and recognized glucocorticoid drug for the treatment of spinal cord injury; it is also the only Food and Drug Administrationapproved drug for the clinical treatment of $\mathrm{ASCl}$ in the United States ${ }^{7}$. In response to spinal cord injury, MP mediates antioxidative, antiinflammatory, and immunosuppressive effects; stabilizes cell and lysosomal membranes; reduces medullospinal tissue deficiency at the injured site; improves blood flow to the injured spinal cord segment; reduces edema; increases the activity of $\mathrm{Na}+\mathrm{K}+$-dependent ATP enzyme; increases the resting potentials and excitabilities of spinal cord motor fibers; and promotes the generation and conduction of spinal cord impulses ${ }^{8}$. In this study, we observed the impact of MP on medullospinal edema in rats with $\mathrm{ASCl}$, and investigated the Kir4.1- and AQP4-related mechanisms of MPmediated suppression of medullospinal edema in rats with $\mathrm{ASCl}$.

\section{- Methods}

This study was carried out in strict accordance with the recommendations in the Guide for the Care and Use of Laboratory Animals of the National Institutes of Health. The animal use protocol has been reviewed and approved by the Institutional Animal Care and Use Committee (IACUC) of Jilin University.

Healthy, male Sprague Dawley (SD) rats $(250-300 \mathrm{~g})$ were provided by the Experimental Animal Center of Jilin University; rat breeding and experimental manipulations were performed in accordance with the management and protection requirements for experimental animals. The rats were bred by special individuals, and maintained with 6 rats to a cage, with free access to 
food and drinking water on a 12-h light/dark cycle, at $22^{\circ} \mathrm{C} \pm 3^{\circ} \mathrm{C}$. We utilized MP (SigmaAldrich, USA); a BCA protein concentration detection kit, polyvinylidene fluoride (PVDF) membranes, 100 ug of protein were loaded per lane, and protein molecular weight standards (Invitrogen, USA); anti-AQP4 (PA1220, BOSTER, China) and anti--Kir4.1 (A02619, BOSTER, China) monoclonal antibodies, anti- $\beta$-actin primary antibody (1:1000 dilution, WL0002, wanleibio, China), and horseradish peroxidase conjugated anti-rabbit secondary antibody $(0.2$ $\mu \mathrm{g} / \mathrm{ml}$, WLA023, wanleibio, China), a vertical electrophoresis and membrane-transferring system (Hoefer, USA); and a quantitative polymerase chain reaction (PCR) instrument (Exicycler 96, BIONEER).

\section{Experimental grouping and the establishment of an ASCl animal model}

SD rats were randomly divided into control, sham, $\mathrm{ASCl}$, and MP groups, with 10 rats in each group. After weighing them, we anesthetized the rats by intraperitoneal injection of $10 \%$ chloral hydrate $(3 \mathrm{mg} / \mathrm{kg})$; we then fixed them in the prone position on the operating table, removed their back fur, and disinfected their skin. The T6 spinous process was set as the center, and a single, approximately $5-\mathrm{cm}$ incision was made along the middle of the back to expose the T5 to T7 spinous processes and lamina; the T6 spinous process and lamina were removed to reveal approximately $0.5 \mathrm{~cm}$ of dural sac. The width of a spinal cord clip was adjusted to $1 \mathrm{~mm}$ and its 2 blades were placed along the bilateral sides of the dural sac of the rats in the $\mathrm{ASCl}$ and MP groups, then quickly adjusted to $2 \mathrm{~mm}$ and clipped to the spinal cord for approximately $1 \mathrm{~min}$; spasm and swing of the rats' lower limbs and tail indicated that the spinal cord had been damaged, then the spinal cord clip was removed, The bilateral deep fascia, subcutaneous tissues, and skin were sutured. The control group did not undergo surgery, and the sham-group rats were incised to expose the dural sac without the use of a spinal cord clip to damage the spinal cord. After the surgery, the rats from each group were fed separately, and assisted with urination and defecation in the early post-operative stages. The rats in the MP group were slowly injected with $30 \mathrm{mg} / \mathrm{kg} \mathrm{MP}$ solution via the tail vein within $1 \mathrm{~h}$ of the $\mathrm{ASCl}$ surgery; the total, $23-h$ dose was calculated according to $5.4 \mathrm{mg} / \mathrm{kg} / \mathrm{h}$, and injected once every $8 \mathrm{~h}$; the injection time points were postoperative days 3 and 7 .

\section{Tarlov scoring}

A modified Tarlov scoring method was applied to score the motor functions of the rats in each group at 8 h, 24 h, $3 d$, and $7 d$ post-surgery, to determine the success of the modeling. The scoring criteria were as follows: 0 , complete paralysis without reaction to lower limb acupuncture; 1, complete paralysis with reaction to lower limb acupuncture, but inability to move limbs; 2 , limb movement, but inability to stand or stand stably ( $<5 \mathrm{~s}) ; 3$, ability to stand, but not walk; 4 , ability to walk a few unstable steps; 5 , ability to walk slowly but inflexibly with some defects; 6 , ability to walk normally. The rats with motor nerve function scores from 0 to 2 were deemed to successfully model $\mathrm{ASCl}$, and were selected for subsequent experiments.

\section{Water content detection in medullospinal tissues}

Five rats in each group were randomly selected, and anesthetized with $10 \%$ chloral hydrate $(3 \mathrm{mg} / \mathrm{kg})$; the incision of the original approach was reopened, the paraspinal muscles were peeled to expose the T5 to T7 lamina, then the T5 to T7 spinal cord segments were removed. The medullospinal tissues of each group were weighed to determine the wet weights, then placed in an $80^{\circ} \mathrm{C}$ oven for $48 \mathrm{~h}$ before obtaining their dry weights. The water content of the spinal cord was calculated 
according to the following formula: (wet weight - dry weight)/wet weight $\times 100 \%$.

Hematoxylin \& Eosin staining of medullospinal tissues

The T5 to T7 spinal cord segments were collected from the remaining 5 rats in each group. Part of the medullospinal tissues were fixed in neutral formalin, embedded in paraffin, and sectioned; Sections of $5 \mu \mathrm{m}$ were stained with hematoxylin \& Eosin ( $\mathrm{H} \& \mathrm{E})$ to observe the pathological changes in the medullospinal tissues, and the rest of the sections were used for immunofluorescence detection. The remaining medullospinal tissues were used for western blotting.

\section{Immunofluorescence detection}

Each section was dried in a $65^{\circ} \mathrm{C}$ oven for $30 \mathrm{~min}$, then dewaxed in grade I and II xylene solutions. After soaking in a gradient of ethanol solutions, the sections were rinsed with PBS and subjected to a 10-min antigen retrieval. Bovine serum albumin blocking solution (1\%) was added to the sections for $10 \mathrm{~min}$, followed by rinsing with PBS, and overnight incubation with the PBS-diluted primary antibodies against Kir4.1 (1:50) and AQP4 $(1: 100)$ in a wet box at $4{ }^{\circ} \mathrm{C}$. The diluted fluorescent secondary antibodies were then added to the sections and allowed to stand at room temperature for $60 \mathrm{~min}$. After washing, DAPI was added to the sections for nuclear staining. We then added half a drop of antifluorescent quencher to the sections and mounted them with coverslips. The sections were then observed and photographed under a fluorescence microscope.

\section{Western blot analysis}

We placed $100 \mathrm{mg}$ of medullospinal tissue into $1 \mathrm{ml}$ of protein lysate solution and quickly homogenized to prepare tissue homogenates. We then extracted total protein, and determined the concentration by BAC. We boiled $100 \mu$ l of the samples in $2 \times$ SDS gel loading buffer, then performed 1-h gel electrophoresis to separate the proteins. The membrane was washed in TBS buffer ( $200 \mathrm{mM}$ Tris [pH 7.5], $200 \mathrm{mM} \mathrm{NaCl}$ ) and blocked with $10 \%$ powdered milk in TBS for $1 \mathrm{~h}$. The membrane was washed twice in TBS. The primary antibody was added in milk-TBS buffer for $2 \mathrm{~h}$ at room temperature (or at $4^{\circ} \mathrm{C}$ overnight). The membrane was then washed three times in TBS TT buffer (TBS with $2 \%$ Triton $X$ and $0.5 \%$ Tween). The goat antirabbit secondary antibody was then added and incubated at room temperature for $6 \mathrm{~h}$. After developing the film, we performed a semi-quantitative analysis on the proteins, with the control group as $100 \%$, to analyze the expression of the target proteins.

\section{Statistical analysis}

SPSS18.0 statistical software was used for statistical analyses. The normally distributed measurement data were expressed as $\bar{x} \pm \mathrm{s}$, the intergroup averages were compared by ANOVA, and multiple comparisons were made among the groups by the least significant difference t-test; comparisons where $P<0.05$ were considered statistically significant.

\section{Results}

The impact of MP on post-ASCl motor nerve functions

Compared with the sham group, the $\mathrm{ASCl}$ group had significantly reduced motor nerve function scores at each time point ( $P$ $<0.05)$; compared with the ASCl group, the MP group had significantly increased motor function scores on post-operative days 3 and 7 ( $P$ $<0.05$ ) (Figure 1). We did not detect significant differences at any time point between the sham and control groups, indicating that the incision alone did not damage motor function in rats $(P>0.05)$. 


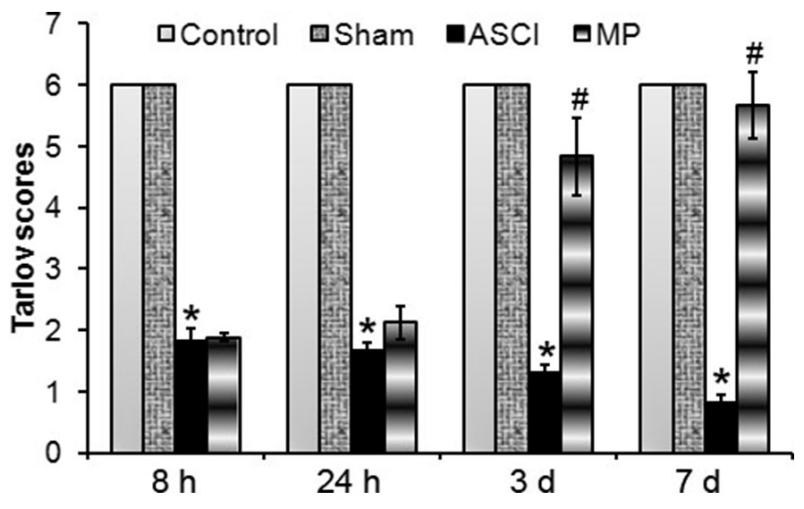

Figure 1 - Impacts of MP on Tarlov scores at different post-ASCl time points in SD rats $\left(\bar{x}_{ \pm} \mathrm{SD}\right.$, $\mathrm{n}=10$ ). Compared with Group sham, $* \mathrm{P}<0.05$; compared with Group ASCI, \#P $<0.05$.

\section{Effects of MP on tissue water content in rats} with $\mathrm{ASCl}$

Seven days after injury, the water content in the $\mathrm{ASCl}$ group was significantly higher than that in the sham group (76.91 \pm 8.64 vs. $60.85 \pm 5.37, \mathrm{P}<0.05)$; however, compared with that in the $\mathrm{ASCl}$ group, the water content in the MP group was significantly reduced

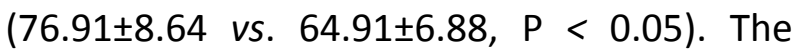
comparison between the sham and control groups showed no significant difference in the water content, indicating that the surgery did not result in medullospinal edema in rats (60.85 \pm 5.37 vs. $60.65 \pm 4.27, \mathrm{P}>0.05)$.

\section{MP alters spinal cord morphology post-ASCI}

The rats in the control and sham groups had normal spinal cord morphologies; however, the medullospinal tissues of the rats in the $\mathrm{ASCl}$ group exhibited extensive hemorrhaging in the central tube and the central gray matter, as well as severe edema in the perivascular tissues and neurons. In the $\mathrm{ASCl}$ group, the number of neurons was reduced, the cell gaps were widened, the nuclei were condensed, partial medullospinal necrosis had occurred, partial spinal white matter degeneration had occurred, and cysts and vacuoles had formed. Our results showed that in the MP group, the boundaries between spinal gray matter and white matter were clearer than $\mathrm{ASCl}$ group. The range of bleeding and phenomenon of nuclear condensation were reduced. The edema in perivascular tissues and neurons was also reduced, the edema volume was improved (Figure 2).

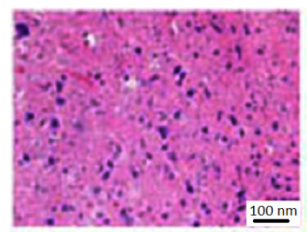

Control

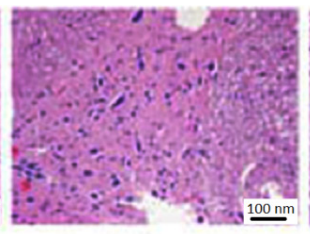

Sham

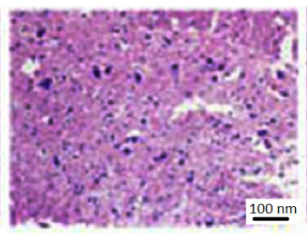

ASCl

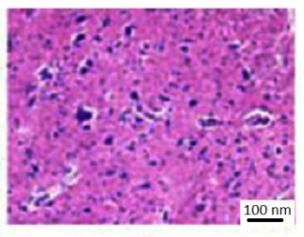

MP

Figure 2 - Impacts of MP on post-ASCI spinal cord morphologies (HE $\times 200)$.

Effect of MP on the expression of AQP4 and Kir4.1 in post-ASCI medullospinal tissues

Compared with that in the sham group, the expression of AQP4 and Kir4.1 in the ASCI group was significantly increased $(P<0.05)$. However, in the MP group, compared with that in the $\mathrm{ASCl}$ group, the expression of AQP4 and Kir4.1 was significantly downregulated $(P<0.05)$ (Figure 3); there was no significant difference in the expression of AQP4 or Kir4.1 between the sham and control groups $(P>$ 0.05). 

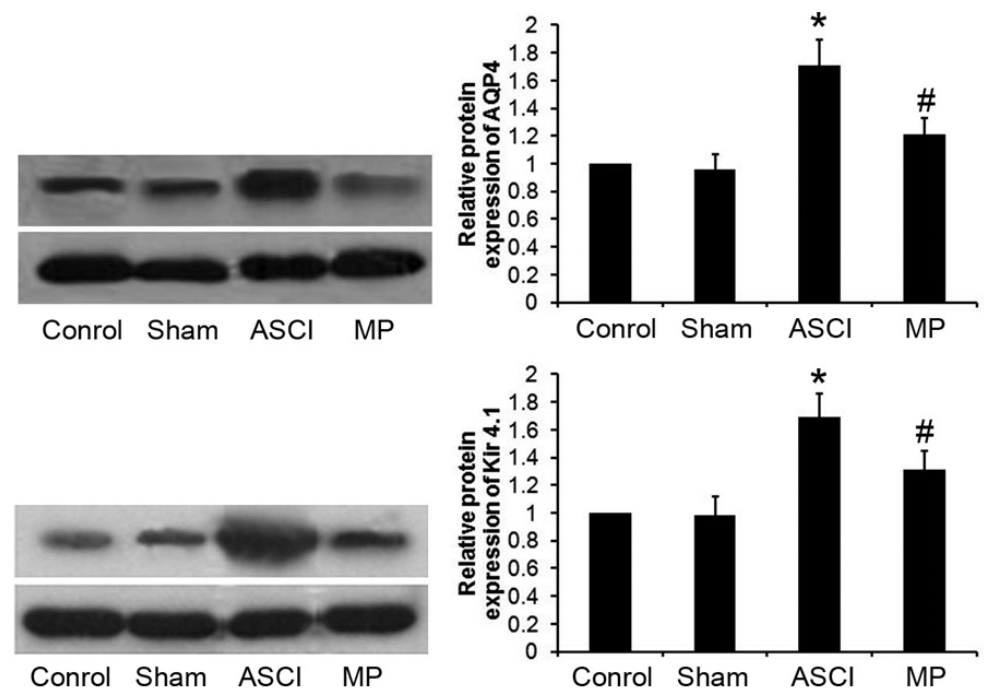

Figure 3 - Impacts of MP on expressions of AQP4 and Kir4.1 in post-ASCI medullispinal tissues $\left(\bar{x}_{ \pm} \mathrm{SD}, \mathrm{n}=10\right)$. Compared with Group sham, *P $<0.05$; compared with Group ASCl, \#P $<0.05$.

Detection of AQP4 and Kir4.1 coexpression in post-ASCI medullospinal tissues by immunofluorescence

AQP4 and Kir4.1, which were coexpressed in post-ASCl medullospinal tissues, were mostly distributed in the spinal gray matter and less abundant in the spinal white matter; they were abundantly expressed on the membranes of the spinal pia mater, the

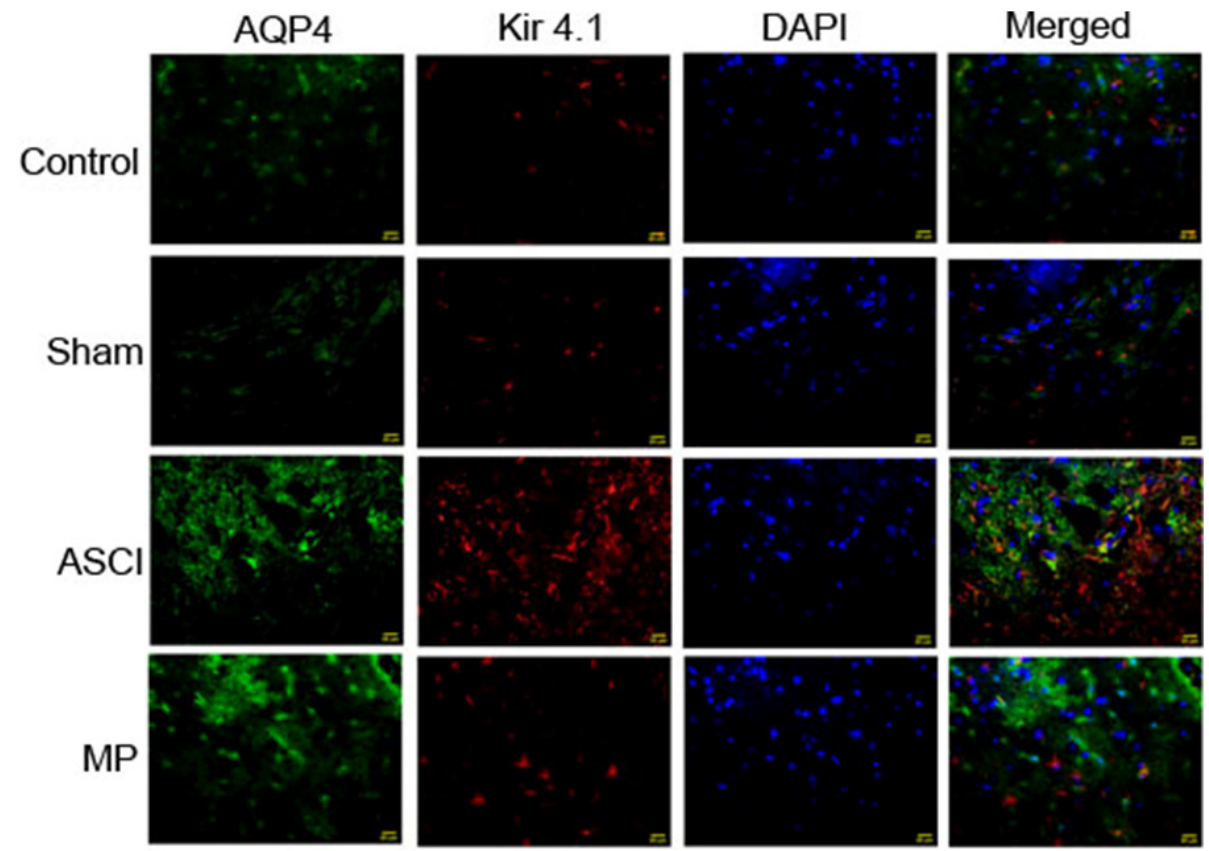

Figure 4 - Co-expression detection of AQP4 and Kir4.1 by immunofluorescence. 


\section{Discussion}

$\mathrm{ASCl}$ is a common cause of motor dysfunction in modern society, where it is primarily caused by sports, falls, violence, or traffic accidents ${ }^{9}$. With the continuous developments of modern society, the probability of $\mathrm{ASCl}$ is increased yearly; most patients are young or middle-aged, and suffer from paraplegia, loss of the ability to work, motor dysfunction, or even death, which results in heavy burdens on society and the patients' families. ASCl includes primary and secondary spinal cord injury processes. The former refers to the direct damage caused by spinal canal destruction and dislocation, which compress the spinal cord and cause fractures; usually, this kind of external force-mediated injury is irreversible. Secondary injury follows primary injury, and is caused by a variety of factors. This kind of injury can occur within several minutes or a few days, and includes medullospinal edema, spinal cord hemorrhage, changes to free radicals in local tissues, microtubule circulation disorder, or reperfusion injury, which can harm the spinal cord by inducing devastating lesions in the tissues around the foci, followed by gradual neurological dysfunction ${ }^{10}$. The degree of secondary spinal cord injury is greater than that of primary injury, but most cases are reversible or preventable.

Medullospinal edema is one of the key pathological processes of secondary spinal cord injury; it has an important impact on the recovery of spinal cord function, and affects the prognosis and treatment of spinal cord injury. The degree of post-ASCl edema is closely related to motor functions; medullospinal edema starts from the central portion of the spinal gray matter, then gradually spreads to the surrounding tissues and the spinal white matter, causing injury aggravation owing to compression of the spinal cord and an abnormal microtubule environment ${ }^{11}$. The occurrence and development of medullospinal edema induces ischemia and hypoxia, or even death in severe conditions, in neurons, which eventually leads to neuronal dysfunction; therefore, identifying strategies to reduce the occurrence of post-ASCl edema is a nonnegligible issue. Currently, the lack of effective treatments for $\mathrm{ASCl}$ is a worldwide problem; secondary $\mathrm{ASCl}$ typically causes catastrophic damage to patients, so effective treatments could preserve and improve peri-lesion nerve tissue function, thereby extending and improving the lives of patients with $\mathrm{ASCl}^{12}$. Therefore, measures that reduce the loss of neuronal functions would have research and therapeutic value.

$M P$ is the most effective drug currently recognized for the treatment of $\mathrm{ASCl}$, but its specific mechanisms of action have not been identified. Its main mechanism is to inhibit the generation of free oxygen radicals, thus resisting the peroxidation of blood lipids; meanwhile, it could also improve microtubule circulation, inhibit inflammation, reduce intracellular calcium influx, and maintain the excitability of neurons $^{13}$. In this study, intervention with MP improved the neurological function scores of rats with $\mathrm{ASCl}$, and reduced the water content and degree of edema in their medullospinal tissues.

AQPs are a family of water-specific membrane proteins that exist on cell membranes, where they form pores and control the exchange of extracellular and intracellular water. Currently, a total of 13 AQPs (AQP0-AQP12) have been found in mammals; AQP4 is the most widely expressed and distributed in the nervous system, especially in the brain and the medullospinal tissues ${ }^{14}$. The main functions of AQP4 are to regulate the exchange of intracellular and extracellular water molecules, provide a transportation route for the rapid and plentiful movement of water, participate in water regulation in 
vivo, and maintain the water balance in vivo. AQP4 has been reported to participate in the formation of tissue edema caused by postinjury hemorrhage, inflammation, or tumors ${ }^{15}$. Manley found that the expression of AQP4 in edematous brain tissue was higher than that in normal brain tissue, and that the deficiency of AQP4 reduced edema in the brain and capillaries ${ }^{16}$. Solenov et $a l .{ }^{17}$ found that edema was significantly reduced in rat medullospinal tissues that lacked AQP4. Nesic also reported that AQP4 is expressed in the spinal gray matter of normal rats, and that this expression tended to increase after $\mathrm{ASCl}$; furthermore, this trend was spatiotemporally related to the water content in the spinal cord, and could last for several days ${ }^{18}$. Therefore, the expression of AQP4 positively correlated with medullospinal edema, and the downregulation of AQP4 could reduce its severity.

Kir has strong effects on $\mathrm{K}+$ influx and can shift extracellular $\mathrm{K}+$ into cells. Recent studies found that Kir participated in water transportation, and was closely related to edema; moreover, the expression of Kir4.1 was increased in edematous tissues ${ }^{19}$. Zhang ${ }^{20}$ found that the expression of Kir4.1 in rats with focal cerebral ischemia and reperfusion positively correlated with the degree of cerebral edema. However, Kir4.1 was transported via the AQP4coupled mediating water, not independently ${ }^{20}$. The water balance regulatory roles of AQP4 were also closely related to Kir4.121. Nagelhus ${ }^{22}$ found strict colocalization between AQP4 and Kir4.1, and Amiry ${ }^{23}$ confirmed that AQP4mediated water molecule transportation was related to the siphoning of $\mathrm{K}+$. Therefore, the coexpression of AQP4 and Kir4.1 indicated interaction between them at the molecular level, and their coexpression was associated with normal water transportation in brain tissues.

We showed that the expression of AQP4 and Kir4.1 in the medullospinal tissues was significantly increased in the $\mathrm{ASCl}$ group compared with that in the sham group; they exhibited the phenomenon of co-expression, which was also significantly upregulated in injured rats. In the MP group, compared with that in the $\mathrm{ASCl}$ group, however, the expression of AQP4 and Kir4.1 in the medullospinal tissues was significantly decreased, as was their coexpression. These results suggested that the increased coexpression and expression levels of AQP4 and Kir4.1 might be involved in the formation of medullospinal edema and the induction of pathological changes in medullospinal tissues, as part of secondary ASCl; the inhibitory effects of MP on medullospinal edema might be associated with its reduction of the coexpression and expression levels of AQP4 and Kir4.1. Recent study demonstrated that MP administration following $\mathrm{SCl}$ reduced AQP4 expression and exacerbates edema ${ }^{24}$. The Cabrera-Aldana's ${ }^{24}$ study showed that $\mathrm{SCl}$ increased AQP4 expression in the spinal cord white matter and that MP diminished such increase to baseline levels. Moreover, MP increased the extravasation of plasma components after $\mathrm{SCl}$ and enhanced tissue swelling and edema. Our results showed that MP inhibited medullospinal edema in rats with $\mathrm{ASCl}$, possibly by reducing the coexpression of AQP4 and Kir4.1 in medullospinal tissues. The inconsistency between the two studies might be attributable to the difference in $\mathrm{SCl}$ models and types of edema.

\section{- Conclusions}

Methylprednisolone inhibits medullospinal edema in rats with acute spinal cord injury, which might be related to its roles in reducing the coexpression and expression levels of AQP4 and Kir4.1 in the medullospinal tissues. This study could provide a theoretical and experimental basis for the application of glucocorticoids in treating $\mathrm{ASCl}$, as well as provide new ideas for developing AQP4- and Kir4.1-targeting drugs for the treatment of $\mathrm{ASCl}$. 


\section{References}

1. Varma AK, Das A, Wallace G 4th, Barry J, Vertegel AA, Ray SK, Banik NL. Spinal cord injury: a review of current therapy, future treatments, and basic science frontiers. Neurochem Res. 2013 May;38(5):895-905. doi: 10.1007/s11064-013-0991-6.

2. Peterson SL, Anderson AJ. Complement and spinal cord injury: traditional and non-traditional aspects of complement cascade function in the injured spinal cord microenvironment. Exp Neurol. 2014 Aug;258:35-47. doi: 10.1016/j. expneurol.2014.04.028.

3. Oklinski MK, Lim JS, Choi HJ, Oklinska P, Skowronski MT, Kwon TH. Immunolocalization of Water Channel Proteins AQP1 and AQP4 in Rat Spinal Cord. J Histochem Cytochem. 2014 Aug;62(8):598611. doi: 10.1369/0022155414537495.

4. Wang BF, Cui ZW, Zhong ZH, Sun YH, Sun QF, Yang GY, Bian LG. Curcumin attenuates brain edema in mice with intracerebral hemorrhage through inhibition of AQP4 and AQP9 expression. Acta Pharmacol Sin. 2015 Aug;36(8):939-48. doi: 10.1038/ aps.2015.47.

5. Jiang $X$, Huang $Y$, Lin W, Gao D, Fei $Z$. Protective effects of hydrogen sulfide in a rat model of traumatic brain injury via activation of mitochondrial adenosine triphosphate-sensitive potassium channels and reduction of oxidative stress. J Surg Res. 2013 Oct;184(2):e27-e35. doi: 10.1016/j. jss.2013.03.067.

6. Yan JH, Khatibi NH, Han $\mathrm{HB}, \mathrm{Hu} Q$, Chen $\mathrm{CH}$, Li L, Yang XM, Zhou CM. p53-induced uncoupling expression of aquaporin-4 and inwardly rectifying $\mathrm{K}+4.1$ channels in cytotoxic edema after subarachnoid hemorrhage. CNS Neurosci Ther. 2012 Apr;18(4):334-42. doi: 10.1111/j.17555949.2012.00299.x.

7. Karamouzian $S$, Akhtarshomar S, Saied A, Gholamhoseinian A. Effects of methylprednisolone on neuroprotective effects of delay hypothermia on spinal cord injury in rat. Asian Spine J. 2015 Feb;9(1):16. doi: 10.4184/asj.2015.9.1.1.

8. Wu Y, Collier L, Pan J, Qin W, Bauman WA, Cardozo CP. Testosterone reduced methylprednisolone-induced muscle atrophy in spinal cord-injured rats. Spinal Cord. 2012 Jan;50(1):57-62. doi: 10.1038/ sc. 2011.91.

9. Jia $X$, Kowalski RG, Sciubba DM, Geocadin RG. Critical care of traumatic spinal cord injury. J Intensive Care Med. 2013 Jan-Feb;28(1):12-23. doi: $10.1177 / 0885066611403270$.

10.Grant RA, Quon JL, Abbed KM. Management of acute traumatic spinal cord injury. Curr Treat Options Neurol. 2015 Feb;17(2):334. doi: 10.1007/s11940-014-0334-1.

11.Wang YF, Fan ZK, Cao Y, Yu DS, Zhang YQ, Wang YS. 2-Methoxyestradiol inhibits the up-regulation of AQP4 and AQP1 expression after spinal cord injury. Brain Res. 2011 Sep;1370:220-6. doi: 10.1016/j. brainres.2014.12.045.

12.Gensel JC, Zhang B. Macrophage activation and its role in repair and pathologyafterspinal cord injury. Brain Res. 2015 Sep;1619:1-11. doi: 10.1016/j.brainres.2014.12.045.

13. Nash HH, Borke RC, Anders JJ. Ensheathing cells and methylprednisolone promote axonal regeneration and functional recovery in the lesioned adult rat spinal cord. J Neurosci. 2002 Aug;22(16):7111-20. doi: 20026746.

14. Filippidis AS, Kalani MY, Rekate HL. Hydrocephalus and aquaporins: the role of aquaporin-4. Acta Neurochir Suppl. 2012;113:55-8. doi: 10.1007/978-3-70910923-6_12.

15.Verkman AS, Mitra AK. Structureand function of aquaporin water channels. Am J Physiol Renal Physiol. 2000 Jan;278(1):F13-28. PMID: 10644652.

16. Manley GT, Fujimura $M$, Ma T, Noshita $\mathrm{N}$, Filiz F, Bollen AW, Chan P, Verkman AS. Aquaporin-4 deletion in mice reduces brain edema after acute water intoxication and ischemic stroke. Nat Med. 2000 Feb;6(2):159-63. doi: 10.1038/72256.

17.Solenov EI, Vetrivel L, Oshio K, Manley GT, Verkman AS. Optical measurement of swelling and water transport in spinal cord slices from aquaporin null mice. J Neurosci Methods. 2002 Jan;113(1):85-90. PMID: 11741725.

18.Nesic O, Lee J, Ye Z, Unabia GC, Rafati D, Hulsebosch CE, Perez-Polo JR. Acute and chronic changes in aquaporin 4 expression after spinal cord injury. Neuroscience. 
2006 Dec;143(3):779-92. doi: 10.1016/j. neuroscience.2006.08.079.

19.Dibaj P, Kaiser M, Hirrlinger J, Kirchhoff F, Neusch C. Kir4.1 channels regulate swelling of astroglial processes in experimental medullispinal edema. J Neurochem. 2007 Dec;103(6):2620-8. doi: 10.1111/j.14714159.2007.04979.x.

20.Zhao M, Bousquet $E$, Valamanesh $F$, Farman N, Jeanny JC, Jaisser F, BeharCohen FF. Differential regulations of AQP4 and Kir4.1 by triamcinolone acetonide and dexamethasone in the healthy and inflamed retina. Invest Ophthalmol Vis Sci. 2011 Aug;52(9):6340-7. doi: 10.1167/iovs.117675.

21.Tham DK, Moukhles H. Regulation of Kir4.1 and AQP4 expression and stability at the basolateral domain of epithelial MDCK cells by the extracellular matrix. Am J Physiol Renal Physiol. 2011 Aug;301(2):F396-409. doi: 10.1152/ajprenal.00315.2010.

22.Nagelhus EA, Horio $Y$, Inanobe A, Fujita A, Haug FM, Nielsen $S$, Kurachi $Y$, Ottersen
OP. Immunogold evidence suggests that coupling of $\mathrm{K}+$ siphoning and water transport in rat retinal Müller cells is mediated by a coenrichment of Kir4.1 and AQP4 in specific membrane domains. Glia. 1999 Mar;26(1):47-54. PMID: 10088671.

23.Amiry-Moghaddam M, Otsuka T, Hurn PD, Traystman RJ, Haug FM, Froehner SC, Adams ME, Neely JD, Agre P, Ottersen OP, Bhardwaj A. An alpha-syntrophin-dependent pool of AQP4 in astroglial end-feet confers bidirectional water flow between blood and brain. Proc Natl Acad Sci U S A. 2003 Feb;100(4):2106-11. doi: 10.1073/ pnas. 0437946100 .

24. Cabreraaldana EE, Ruelas F, Aranda C, Rinconheredia R, Martínezcruz A, Reyessánchez A, Guizar-Sahagún G, Tovar-y-Romo LB. Methylprednisolone administration following spinal cord injury reduces aquaporin 4 expression and exacerbates edema. Mediators Inflamm. 2017 May;2017(6):1-7. doi: $10.1155 / 2017 / 4792932$.

\section{Correspondence:}

Rui Gu

Department of Orthopaedics

China-Japan Union Hospital, Jilin University

Changchun 130033

China

Phone: +86 43184995117

cnlydoc@126.com

Received: Oct 16, 2017

Review: Dec 18, 2017

Accepted: Jan 19, 2018
Conflict of interest: none

Financial source: none 